\title{
LAS ORGANIZACIONES Y SUS LÍDERES FRENTE A UN NUEVO ESCENARIO*
}

\author{
Kobila, María Teresa \\ Parolin, Marisa Andrea
}

\section{RESUMEN:}

En el mundo un virus, tan inesperado como impensado, obligó a la Organización Mundial de la Salud (OMS) a declarar una pandemia. En ese marco, el trabajo y el empleo en las organizaciones se vieron alterados, despertando el interés por indagar cómo se gestiona y transita ese cambio en las organizaciones. En ese contexto de dificultades y potencialidades, se plantearon los siguientes objetivos: sondear y describir los cambios en las formas de trabajo de las empresas estudiadas, conocer y narrar el rol desempeñado por sus líderes y/o directivos y reflejar los impactos preliminares sobre la cultura organizacional. Se empleó una investigación cualitativa de tipo exploratoria para clarificar la nueva realidad. Debido al aislamiento social, impuesto desde la esfera gubernamental, no se pudieron realizar observaciones personales en el lugar de trabajo. Los contactos se efectuaron vía email y/o comunicaciones telefónicas pactándose días y horarios para las entrevistas, que a posteriori se cometieron virtualmente. La pandemia, entre tantas problemáticas, oportunidades y desafíos infiltró la virtualidad en la esfera social. En tiempos de coronavirus el teletrabajo ha emergido con una nueva estrategia, convirtiendo el tele-trabajo en una capacidad clave tanto para el individuo como para la competitividad organizacional. Factores externos no controlables impactaron en las estrategias, estructuras y cultura de las organizaciones. Las empresas estudiadas, en mayor o menor medida, tuvieron que dar respuestas innovadoras frente a la nueva realidad que desafiaba hasta la supervivencia organizacional. Flexibilizar las estructuras, hacerla más dinámicas y orgánicas, adaptarse a las exigencias del mercado, fueron decisiones a implementar sin tiempo para analizar alternativas. El desempeño de los líderes se orientó a dar respuestas rápidas, y quiénes asumieron una actitud proactiva lograron adaptarse más rápidamente, también es cierto que quiénes aplazaron los cambios hoy están en esta senda. Se presume que quiénes no se adapten a los cambios quedarán marginados del mercado, por ello se piensa que los líderes y/o directivos enfrentan un gran desafío. En este sentido, es esperable que este nuevo escenario sea el inicio de un cambio cultural profundo.

PALABRAS CLAVES: Cambio organizacional- Cultura organizacional- Rol de los líderes.

*Esta ponencia se basa en un poster presentado en las XIV Jornadas de Ciencias, Tecnologías e Innovación de la UNR (2020) como síntesis y primera aproximación de los resultados del presente trabajo de investigación 


\section{ABSTRACT:}

In the world a virus, as unexpected as it was unthinkable, forced the World Health Organization (WHO) to declare a pandemic. In this framework, work and employment in organizations were altered, awakening interest in investigating how this change is managed and carried out in organizations. In this context of difficulties and potentialities, the following objectives were proposed: to survey and describe the changes in the ways of working of the companies studied, to know and narrate the role played by their leaders and / or managers and to reflect the preliminary impacts on culture organizational. An exploratory qualitative investigation was used to clarify the new reality. Due to social isolation, imposed from the governmental sphere, personal observations could not be made in the workplace. The contacts were made via email and / or telephone communications, agreeing days and times for the interviews, which were carried out virtually posteriori. The pandemic, among so many problems, opportunities and challenges, infiltrated verticality into the social sphere. In times of coronavirus, teleworking has emerged with a new strategy, making teleworking a key capacity for both the individual and for organizational competitiveness. Uncontrollable external factors impacted on the strategies, structures and culture of the organizations. The companies studied, to a greater or lesser extent, had to give innovative responses to the new reality that challenged even organizational survival. Making the structures more flexible, making it more dynamic and organic, adapting to market demands, were decisions to be implemented without time to analyze alternatives. The performance of the leaders was oriented to give quick answers, and those who assumed a proactive attitude managed to adapt more quickly, it is also true that those who postponed the changes today are on this path. It is presumed that those who do not adapt to the changes will be marginalized from the market, for this reason it is thought that leaders and / or managers face a great challenge. In this sense, it is expected that this new scenario is the beginning of a profound cultural change.

KEY WORDS: Organizational change- Organizational culture- Role of leaders

\section{INTRODUCCIÓN}

Los cambios son una constante que desafían a las personas y organizaciones. Sean planificados o no siempre comportan decisiones y acciones que impactan en las organizaciones y el ambiente. Los cambios previsibles que, se pueden anticipar en un horizonte de tiempo, son más dables de gestionar, en tanto que, los cambios abruptos o disruptivos, que acaecen imprevistamente ostentan desafíos superiores para los directivos. En el mundo un virus, tan inesperado como impensado, obligó a la Organización Mundial de la Salud (OMS) a declarar una pandemia. En ese marco, el trabajo y el empleo en las 
organizaciones se vieron alterados, despertando el interés por indagar cómo se gestiona y transita ese cambio en las organizaciones, tema que se enmarca en la investigación sobre "Gestión de la Complejidad Cultural en las Organizaciones".

Un tema que plantea numerosos interrogantes aunque, a "prima facie" las indagaciones que interpelan giran en torno a: ¿entienden los directivos y/o líderes los nuevos cambios?, ¿qué papel asumen frente a la presente situación?, ¿lograrán las empresas implementar estrategias de adaptación o cambios?, ¿qué pasó con la planificación?, ¿qué comportamientos, costumbres y/o rituales se produjeron en el seno de las organizaciones?, ¿cambiaron las actitudes y valores de los directivos y/o miembros de la organización?, la estructura organizacional ¿se modificó?, ¿en qué aspectos o medida?, ¿están las organizaciones preparadas para competir en un futuro incierto? Estos cuestionamientos se convirtieron en los motores de investigación para trabajar durante el año 2020. Para esta ponencia se plasmaron tres ejes de trabajo: cambio, líderes y directivos, y cultura organizacional.

No obstante, la incertidumbre y el aparente escenario de crisis replicaban las preguntas cuando una observación superficial del terreno delataba otros tiempos y formas de trabajo, nuevos compromisos y prácticas, en medio de temores, ansiedades, confusiones y desafíos. El cambio irrumpió en el escenario de las organizaciones de la mano de la virtualidad planteando nuevos interrogantes en referidos a las ideas, motivaciones y representaciones de los líderes y personas que allí trabajan.

En este contexto de dificultades y potencialidades, se plantearon los siguientes:

\section{OBJETIVOS}

- Sondear y describir los cambios en las formas de trabajo de las empresas estudiadas.

- Conocer y narrar el rol desempeñado por sus líderes y/o directivos.

- Reflejar los impactos preliminares sobre la cultura organizacional.

\section{METODOLOGÍA}

En relación a la problemática y los objetivos esbozados precedentemente se empleó una investigación cualitativa de tipo exploratoria para clarificar la nueva realidad.

Este proceso de investigación está en una etapa preliminar de indagación. Estaba previsto realizar las entrevistas en seis (6) organizaciones, pero debido a la complicada situación contextual y la limitante del factor tiempo, finalmente se efectuó el relevamiento de datos en

\footnotetext{
${ }^{1}$ Proyecto de investigación 80020190100057 R, dirigido por la Dra. María Teresa Kobila, radicado en la Facultad de Ciencias Económicas y Estadística de la U.N.R
} 
tres empresas rosarinas del rubro servicios. Las organizaciones estudiadas contaban con más de treinta (30) personas en su plantel.

Debido al aislamiento social, impuesto desde la esfera gubernamental, no se pudieron realizar observaciones personales en el lugar de trabajo. Los contactos se efectuaron vía email y/o comunicaciones telefónicas pactándose días y horarios para las entrevistas, que a posteriori se cometieron virtualmente.

La modalidad indagatoria fue flexible, pudiéndose obtener una visión ampliada del panorama situacional organizacional. Las entrevistas vía "meet" con los directivos posibilitó conocer, de primera mano, sus opiniones en relación a las nuevas modalidades de trabajo. Si bien se proyectó una "primera aproximación" al tema, se logró copiosa información novedosa que posibilitó construir esta ponencia. Del mismo modo resultó valiosa para poner a prueba y ampliar nuestro guión de entrevista y orientar el rumbo de próximas investigaciones.

El relevamiento se efectuó entre el 15 de mayo y el 15 de julio de 2020, quedando abiertas las puertas para ampliar información a futuro y de manera más detallada.

\section{MARCO REFERENCIAL}

La gestión del cambio busca facilitar los procesos de transformación. Frecuentemente, son procesos largos y difíciles. Sin embargo, en otras ocasiones la realidad se complica y no da licencia a los directivos y/o líderes que tienen la responsabilidad de conducir los destinos de las organizaciones y deben tomar decisiones expeditivas en pos de resultados satisfactorios.

Es conocido que los cambios impactan en la cultura organizacional (Robbins y Coulter, 2018), y la naturaleza del trabajo directivo se ve alternada (Mintzberg, 1983). También, se sabe que el cambio organizacional es necesario porque las organizaciones requieren adaptarse a las trasformaciones que operan en el contexto -economía, mercado, competencia, tecnología, etc., aunque puedan sobrellevar efectos negativos de adaptación derivados de temores, incertidumbre, sentimientos de pérdida e intereses personales amenazados, demandando un trabajo colaborativo entre líderes y colaboradores (Kotter,1995).

No existen recetas ni fórmulas mágicas para gestionar el cambio. Cada empresa debe adaptarla a su medida. Cada organización debe analizar que decisiones y acciones tomar para incrementar su valor económico y social y ello requiere de líderes organizacionales competentes, capaces de adecuarse a la realidad, hoy un nuevo mundo virtual, donde las nuevas tecnologías están cambiando y amenazan con transformar a las organizaciones.

Toda organización se asienta en tres pilares fundamentales: estrategia, estructura y cultura que se retroalimentan mutuamente. La estrategia refiere a la forma en que la empresa 
intenta alcanzar sus objetivos y la visión compartida, la estructura representa como se organizan sus recursos humanos y materiales, y la cultura organizacional, compuesta por distintos elementos.

Según Schein, la cultura se compone por una parte visible, a veces, tangibles tales como los llamados artefactos- edificios, mobiliario, equipamiento, vestimentas, etc.-, el lenguaje, los rituales y las costumbres; y otra parte no visible o intangible que constituye su esencia principios, valores y presunciones básicas-. "La cultura es aprendida, evoluciona con nuevas experiencias y puede ser cambiada si llega a entenderse la dinámica del proceso de aprendizaje" (Schein, 1985:25). No obstante, en todo proceso de cambio sus aspectos básicos o invisibles son más difíciles de modificar.

\section{RESULTADOS PRELIMINARES}

Afín al marco referencial y las preguntas de investigación, los resultados se agruparon en categorías teniendo en cuenta aspectos comunes derivados de las prácticas laborales. Las tres empresas estudiadas, tuvieron que adaptar sus formas de trabajo frente al impacto tecnológico derivado de la pandemia. El Covid-19 visualizado como una amenaza a nivel global impactó en todas las personas, sectores y organizaciones, pero en modos diferentes, según los siguientes aspectos:

\section{1- Referidos a la organización del trabajo}

En nuestra sociedad aún prevalece la cultura presencial. Los entrevistados manifestaron encontrarse frente a una situación desconocida, sin posibilidad de planificación. Las organizaciones se vieron obligadas a incorporar procesos tecnológicos y aceptar el teletrabajo como una alternativa para sobrevivir en el mercado. Sólo una de las tres tenía sus sistemas medianamente preparados ya que venían aplicando parcialmente esta modalidad. El resto se vio enfrentado a un nuevo escenario. Un entrevistado manifestó:

"Para nosotros esta nueva forma de trabajar no fue fácil, tanto para nosotros como para el personal, cada uno con una problemática familiar distinta. Además, cada empleado tiene diferentes niveles de conocimientos y no hubo tiempo para una capacitación previa, pero no nos quedó otra".

El trabajo a distancia supuso no sólo adecuar los sistemas informáticos y trasladar equipos a los domicilios de los trabajadores afectados si no también acostumbrarse a la flexibilidad horaria, la comunicación virtual con sus empleados, asesores, clientes y proveedores y otras prácticas antes impensadas.

Por políticas de distanciamiento social, se ha tenido que recurrir a recursos y procesos que antes no se contemplaban, ya sea por resistencia o simplemente miedo a invertir en 
procesos tecnológicos. El teletrabajo o home office supone formas distintas de pensar y actuar para empresarios, directivos y colaboradores.

Por otro lado, también implicó una oportunidad para potenciar otras variables de marketing como por ejemplo incrementar la presencia en la Web o desarrollo del e-commerce.

\section{2- Referidos al rol de los directivos/ líderes}

En estas empresas, los ahora llamados "telelíderes" debieron rápidamente mejorar y/o incorporar nuevos conocimientos digitales a la vez que potenciar sus competencias blandas referidas a formas diferentes de motivar, de comunicar, controlar y hasta de evaluar a sus equipos virtuales. En mayor o menor medida, los directivos tuvieron que cambiar de actitud frente al cambio. Un empresario expresó: "Fue difícil, pero lo fuimos logrando, era la única manera de que el personal tuviera confianza y aumentara su productividad. Es muy complicado controlar a distancia".

Entre las funciones comunes, que los directivos y/o líderes de estas organizaciones, realizan a diario, se mencionan: generar reuniones virtuales, inspirar seguridad, motivar virtualmente y convertir amenazas en oportunidades. Sin embargo, a través de una lectura más profunda de los dichos, se infiere que no todos los directivos han podido, en tan corto plazo, incorporar todas esas competencias en la misma medida; algunos, aún lo están intentando con mucho esfuerzo y otros, sobre todo los más antiguos, se resisten y les cuesta a aceptar estos cambios.

\section{3- Referidos al impacto en la cultura organizacional}

La llamada cultura digital, teletrabajo o home office implica cambios en las actitudes y acciones de los directivos, líderes y colaboradores. De ellos se espera mayor flexibilidad o capacidad de adaptación a esta nueva realidad, mayor autonomía y compromiso y responsabilidad. El mundo ya no será el mismo. Cuestiones como el presencialismo, los horarios de entrada y salida, los traslados al lugar de trabajo, la oficina en casa, la gestión del tiempo, la manera de medir el desempeño son temas de discusión.

En este sentido, los cambios percibidos en las tres empresas elegidas se reflejan en modificaciones en las costumbres (formas de saludar, por ej.), rituales, (mates compartidos, almuerzos con compañeros), reuniones presenciales, intercambios con sus superiores, espacios físicos, recursos tecnológicos y formas de hacer el trabajo que afectan directamente el comportamiento de sus integrantes y las relaciones con los stakeholders o grupos de interés: clientes, proveedores, entes gubernamentales, entre otros.

Del relevamiento realizado sólo fue posible detectar transformaciones en los aspectos tangibles de la cultura según menciona Schein. Estos cambios en los artefactos podrían ser el puntapié de un verdadero cambio cultural. Por ahora sólo se visualiza la punta del iceberg sin embargo, de los relatos de los directivos de estas organizaciones, se perciben cambios 
en los modos de comportarse y actuar de los miembros de la organización que van impregnando los niveles más profundos de la cultura.

\section{A MODO DE REFLEXION}

La pandemia, entre tantas problemáticas, oportunidades y desafíos infiltró la virtualidad en la esfera social. En particular, en el ámbito organizacional irrumpió un nuevo modo de comunicarse, interactuar y trabajar. ¿Por qué no pensar en un nuevo paradigma? Es innegable que el nuevo escenario está siendo estudiado desde diversas disciplinas y miradas.

En tiempos de coronavirus el teletrabajo ha emergido con una nueva estrategia, convirtiendo el teletrabajo en una capacidad clave tanto para el individuo como para la competitividad organizacional.

Factores externos no controlables impactaron en las estrategias, estructuras y cultura de las organizaciones. Las empresas estudiadas, en mayor o menor medida, tuvieron que dar respuestas innovadoras frente a la nueva realidad que desafiaba hasta la supervivencia organizacional. Flexibilizar las estructuras, hacerla más dinámicas y orgánicas, adaptarse a las exigencias del mercado, fueron decisiones a implementar sin tiempo para analizar alternativas.

Los responsables de la gestión se vieron frente a una encrucijada donde no había margen para trazar planes a mediano o largo plazo. El desempeño de los líderes se orientaba a dar respuestas rápidas, y quiénes asumieron una actitud proactiva lograron adaptarse más rápidamente, también es cierto que quiénes aplazaron los cambios hoy están en esta senda. Se presume que quiénes no se adapten a los cambios quedarán marginados del mercado, por ello se piensa que los líderes y/o directivos enfrentan un gran desafío.

En este sentido, es esperable que este nuevo escenario sea el inicio de un cambio cultural profundo. Los directivos y/o líderes debieran estar repensando sus estrategias, estilos de gestión y qué cultura será funcional a los fines organizacionales y bienestar de sus colaboradores.

Como reflexión final y a partir de la pandemia, se esbozan nuevos interrogantes que serán temas de futuras investigaciones:

- ¿Qué aspectos de las organizaciones se modificarán de forma permanente?

- ¿De qué modo se está redefiniendo el rol de liderazgo?

- ¿Cómo se verá afectado el clima y la cultura organizacional? 


\section{REFERENCIAS BIBLIOGRÁFICAS}

Alles, M. (2020) Gestionar sin estar. [1. Ed]. Ciudad Autónoma de Buenos Aires. Ed. Granica.

Anzorena, O. (2016) Maestría personal: el camino del liderazgo. [5. Ed]. Buenos Aires. Ed. Lea S.A.

Franklin, E. y Krieger, M. (2011). Comportamiento organizacional. Enfoque para América Latina. $\left[1^{\circ}\right.$. Ed]. México. Ed. Pearson-

Hernández Sampieri, R.; C. Fernández Collado Y P. Baptista Lucio (2010) Metodología de la investigación. México: Mc. Graw Hill.

Kotter, John (1995) El líder del cambio. México: Mc Graw Hill.

Lusier, R. y Achua, C. (2013). Liderazgo. Teoría, aplicación y desarrollo de habilidades. México: Cengage Learning.

Melamed, A. (2017) El futuro del trabajo y el trabajo del futuro. [1. Ed]. Ciudad Autónoma de Buenos Aires. Ed. Planeta.

Mintzberg, H. (1983). La naturaleza del trabajo directivo. Buenos Aires: Ariel.

Mintzberg, H. (2007). Safari a la estrategia. Buenos Aires: Granica.

Robbins, S. P. y M. Coulter (2018) Administración. [13 Ed.]. D.F., México: Pearson.

Schein, E. (1985). La cultura empresarial y el liderazgo. Barcelona, España: Plaza \& Janes

Van Morlegan, L. y Ayala, J. (2011). Comportamiento de las personas en las organizaciones. Buenos Aires: Pearson.

Zenger, J. y Folkman, J. (2015). El líder extraordinario. [4. Ed]. España: Profit. 